\title{
Prediction of Clearance in Children from Adults Following Drug-Drug Interaction Studies: Application of Age-Dependent Exponent Model
}

\author{
Iftekhar Mahmood $^{1,2}$ (D) \\ Published online: 13 February 2020 \\ (c) The Author(s) 2020
}

\begin{abstract}
Background and Objective Pharmacokinetic drug-drug interaction (DDI) studies are conducted in adult subjects during drug development but there are limited studies that have characterized pharmacokinetic DDI studies in children. The objective of this study was to evaluate if the DDI clearance values from adults can be allometrically extrapolated from adults to children. Methods Fifteen drugs were included in this study and the age of the children ranged from premature neonates to adolescents (30 observations across the age groups). The age-dependent exponent (ADE) model was used to predict the clearance of drugs in children from adults following DDI studies.

Results The prediction error of drug clearances following DDIs in children ranged from 4 to $67 \%$. Of 30 observations, 17 $(57 \%)$ and 27 (90\%) observations had a prediction error $\leq 30 \%$ and $\leq 50 \%$, respectively.

Conclusion This study indicates that it is possible to predict the clearance of drugs with reasonable accuracy in children from adults following DDI studies using an ADE model. The method is simple, robust, and reliable and can replace other complex empirical models.
\end{abstract}

\section{Introduction}

Drug interaction can lead to modification of a therapeutic response to a drug in an individual due to the exposure of the individual to one or more drugs or chemical substances. Drug interactions include drug-drug interaction (DDI), food-drug interaction, and chemical-drug interaction (for example, drug interaction with alcohol or tobacco) [1]. Drug interaction can alter the pharmacokinetics and/or pharmacodynamics of a drug. In pharmacokinetic drug interactions, the concentrations of one or more drugs are altered by another. This change in concentration in a given drug may be due to changes in absorption, distribution, metabolism, and elimination [1]. The pharmacodynamic interaction can lead to additive, synergistic, or antagonistic effects of a drug [1].

Iftekhar Mahmood

Iftekharmahmood@aol.com

1 Office of Tissue and Advanced Therapies (OTAT), Center for Biologics Evaluation and Research, Food and Drug Administration, 10903 New Hampshire Avenue, Silver Spring, MD 20993-0002, USA

2 Present Address: Mahmood Clinical Pharmacology Consultancy, LLC, 1709, Piccard Dr, Rockville, MD 20850, USA
Like adults, children are also exposed to several drugs that may lead to DDIs; however, the magnitude of the drug interaction ratio (ratio with or without two drugs) may be age-dependent $[2,3]$.

Pharmacokinetic DDI studies are conducted in adults during drug development but there are limited studies that have characterized pharmacokinetic DDI studies in pediatrics [3]. Due to the difficulties in conducting a pediatric DDI PK study, a general and logical view may be that drug interaction studies may not be needed in children because one can extrapolate DDI information from adult data. This view may or may not be applicable to all drugs [3].

The metabolic enzymes and renal elimination mechanisms are quite immature during the early days of life [4-10]. Therefore, the rate and extent of drug metabolism and elimination of drugs are different in children (particularly neonates and infants) of different ages than adults. Similarly, the magnitude of DDIs may be different in neonates and infants than in children [3]. For example, in adults, an interaction can lead to a substantial increase in the clearance of one or both drugs but, due to immature metabolic enzymes, the clearance may be very different (marginal change or no change) in very young children, resulting in subtherapeutic or toxic effects if one tries to extrapolate the DDI information from adults to children. DDI studies in neonates, infants, 


\section{Key Points}

Drug interaction can lead to modification of a therapeutic response to a drug in an individual due to the exposure of the individual to one or more drugs or chemical substances.

Pharmacokinetic drug-drug interaction (DDI) studies are conducted in adults during drug development but there are limited studies that have characterized pharmacokinetic DDI studies in children.

An allometric model (age-dependent exponent model) was used to predict DDI clearance in children (from preterm neonates to adolescents) using DDI adult clearance values following DDI studies.

This study indicated that it was possible to predict the clearance of drugs with reasonable accuracy $(\leq 50 \%$ prediction error) in children from adults following drugdrug interaction studies using an age-dependent exponent model. The method is simple, robust, and reliable and can replace other complex empirical models.

and children are not regularly conducted, but one can find a limited number of such studies in the literature [3].

Drug interaction studies in children indicate that the direction of interaction may be similar to adults, but the magnitude of the interaction may be different [3]. Theoretically, in newborns and infants, one may see negligible or no interaction at all (due to the impact of ontogeny) or the magnitude of interaction may be very different than older children and adults.

The objective of this study was to evaluate if the drug clearance following a DDI can be allometrically extrapolated from adults to children.

\section{Methods}

From the literature, the clearance values of 15 randomly selected drugs were obtained for adults and children, using DDI studies [11-40]. Drugs were chosen when DDI studies were available in both adults and children. The allometric method used for the prediction of drug clearances in children was as follows.

The clearance of drugs with DDIs in children was predicted using an age-dependent exponent (ADE) model, which employs variable exponents as a function of age [41-45]. In this method, different allometric exponents were used for different age groups and the clearance of a drug was predicted in a given age group according to Eq. 1.

$\mathrm{CL}$ in children = adult CL with drug-drug interaction

$$
\times\left(W_{\mathrm{C}} / W_{70}\right)^{b} \text {, }
$$

where 'adult clearance' is the mean adult clearance of a given drug obtained from the literature, and CL in children is the predicted CL following DDIs (the same drugs as for adults); $W_{\mathrm{C}}$ is the weight of a child and $W_{70}$ is the weight of an adult standardized to $70 \mathrm{~kg}$.

Exponent ' $b$ ' in Eq. 1 is age-dependent. The exponents used in Eq. 1 were 1.2 for preterm neonates and 1.1 for term neonates aged $0-3$ months, and 1.0, 0.9, and 0.75 for ages $>3$ months -2 years, $>2-5$ years, and $>5$ years, respectively. The exponents selected in the ADE model [41-45, 49-55] are based on previous experience, observation, and data analysis (discussed later).

\subsection{Statistical Analysis}

The percentage prediction error between the observed and predicted clearance values was calculated according to the following equation:

$\%$ error $=\frac{(\text { Predicted }- \text { observed }) \times 100}{\text { observed }}$.

The percentage prediction error of $\leq 30 \%$ or $\leq 50 \%$ was considered a reasonably accurate prediction.

\section{Results}

In this study, there were 15 drugs and 30 observations across the age groups (preterm to adolescents). The results of the study are shown in Tables 1 and 2. In Table 1, the observed clearance for adults and children with and without interaction ratios are shown. In addition, the data in Table 1 indicate that the interaction ratios between adults and children can be different.

In Table 2, the predicted and observed drug clearance values following DDIs in children are shown. The prediction error of drug clearances following DDIs in children ranged from 4 to $67 \%$. Of 30 observations, only three drugs had a prediction error $>50 \%$, with the highest being $67 \%$, while $17(57 \%)$ and $27(90 \%)$ observations had prediction errors $\leq 30 \%$ and $\leq 50 \%$, respectively.

Overall, when clearances of drugs were predicted in children following DDIs using adult clearance values following a DDI, a reasonably accurate prediction of clearance in children was noted. 
Table 1 Observed clearance $(\mathrm{mL} / \mathrm{min})$ of drugs and interaction ratios with and without drug interaction for adults and children

\begin{tabular}{|c|c|c|c|c|c|}
\hline Drugs & Age, years & Observed alone & Observed interaction & Ratio $^{a}$ & References \\
\hline \multicolumn{6}{|l|}{ Theophylline-phenobarbital } \\
\hline \multirow[t]{3}{*}{ Theophylline } & Adult & $52 \pm 11$ & $70 \pm 23$ & 1.35 & [11] \\
\hline & Premature & $1.3 \pm 0.4$ & $1.5 \pm 1.1$ & 1.15 & [12] \\
\hline & $6-12$ & $40 \pm 10$ & $53 \pm 23$ & 1.33 & [13] \\
\hline \multicolumn{6}{|l|}{ Zidovudine + dideoxyinosine } \\
\hline \multirow[t]{2}{*}{ Zidovudine } & Adult & $3518 \pm 1123$ & $2505 \pm 575$ & 0.71 & {$[14]$} \\
\hline & $3-14$ & $1285 \pm 224$ & $1260 \pm 515$ & 0.98 & {$[15]$} \\
\hline \multicolumn{6}{|l|}{ Dideoxyinosine + zidovudine } \\
\hline \multirow[t]{2}{*}{ Dideoxyinosine } & Adult & $2660 \pm 1297$ & $2766 \pm 686$ & 1.04 & {$[14]$} \\
\hline & $3-14$ & $2488 \pm 2100$ & $2870 \pm 1855$ & 1.15 & {$[15]$} \\
\hline \multicolumn{6}{|c|}{ Levetiracetam + inducers (carbamazepine, oxcarbazepine, phenobarbital, phenytoin) } \\
\hline \multirow[t]{2}{*}{ Levetiracetam } & Adult & $97 \pm 41$ & $107 \pm 49$ & 1.10 & [16] \\
\hline & 9.3 & $70 \pm 29$ & $100 \pm 34$ & 1.43 & [17] \\
\hline Topiramate-carbamazepine & Adult & $33 \pm 17$ & $51 \pm 11$ & 1.55 & [18] \\
\hline Topiramate & $<10$ & $26 \pm 11$ & $42 \pm 9$ & 1.62 & [18] \\
\hline \multicolumn{6}{|l|}{ Topiramate-phenobarbital } \\
\hline Topiramate & Adult & $33 \pm 17$ & $42 \pm 11$ & 1.27 & {$[18]$} \\
\hline Topiramate & $<10$ & $26 \pm 11$ & $46 \pm 19$ & 1.77 & {$[18]$} \\
\hline \multirow[t]{2}{*}{ Topiramate } & $0.9-1.84$ & $8 \pm 2$ & $17 \pm 2$ & 2.13 & {$[19]$} \\
\hline & $2-3.7$ & $11 \pm 3$ & $18 \pm 5$ & 1.64 & {$[19,20]$} \\
\hline \multicolumn{6}{|c|}{ Lamotrigine + carbamazepine and phenytoin } \\
\hline \multirow[t]{3}{*}{ Lamotrigine } & Adult & $50 \pm N A$ & $94 \pm N A$ & 1.88 & {$[21]$} \\
\hline & $<6$ years & $13 \pm 2$ & $32 \pm 11$ & 2.46 & {$[22,23]$} \\
\hline & $7-14$ & $19 \pm 10$ & $80 \pm 27$ & 4.21 & {$[22,23]$} \\
\hline \multicolumn{6}{|l|}{ Lamotrigine + valproic acid } \\
\hline \multirow[t]{3}{*}{ Lamotrigine } & Adult & $50 \pm N A$ & $20 \pm N A$ & 0.40 & {$[21]$} \\
\hline & $0.8-2$ & NA & $6.5 \pm 3.8$ & NA & {$[22]$} \\
\hline & $6-14$ & $19 \pm 10$ & $13 \pm 16$ & 0.69 & {$[22,23]$} \\
\hline \multicolumn{6}{|l|}{ Digoxin-carvedilol } \\
\hline \multirow[t]{2}{*}{ Digoxin } & Adult & $232 \pm 39$ & $201 \pm 34$ & 0.87 & {$[24]$} \\
\hline & $0.08-7.7$ & $35 \pm 12$ & $20 \pm 3$ & 0.57 & {$[25]$} \\
\hline \multicolumn{6}{|l|}{ Artemether-nevirapine } \\
\hline \multirow[t]{2}{*}{ Artemether } & Adult & $10,019 \pm N A$ & $33,057 \pm N A$ & 3.30 & {$[26]$} \\
\hline & 8.3 & $9526 \pm N A$ & $10,103 \pm N A$ & 1.06 & {$[27]$} \\
\hline \multirow[t]{2}{*}{ Lumifentraine lumefantrine } & Adult & $27 \pm N A$ & $35 \pm N A$ & 1.30 & [26] \\
\hline & 7.1 & $10 \pm N A$ & $9 \pm N A$ & 0.90 & {$[27]$} \\
\hline \multicolumn{6}{|l|}{ Etoposide-cyclosporine } \\
\hline Etoposide & Adult & $40 \pm 13$ & $26 \pm 14$ & 0.65 & [28] \\
\hline & $4.4-9.1$ & $26 \pm 6$ & $14 \pm 4$ & 0.54 & [29] \\
\hline & $12.1-17$ & $27 \pm 7$ & $13 \pm 4$ & 0.48 & [29] \\
\hline & $0.83-3.5$ & NA & $7.4 \pm$ NA & NA & {$[30]$} \\
\hline & 14 & NA & $20 \pm 6$ & NA & {$[30]$} \\
\hline Cyclosporine-grapefruit & & & & & \\
\hline Cyclosporine & Adult & $1131 \pm 499$ & $918 \pm 378$ & 0.81 & {$[31]$} \\
\hline & $7-17$ & $2034 \pm 377$ & $1232 \pm 120$ & 0.61 & {$[32]$} \\
\hline Vecuronium-phenytoin & & & & & \\
\hline Vecuronium & Adult & $236 \pm 27$ & $561 \pm N A$ & 2.38 & {$[33]$} \\
\hline & $5-17$ & $378 \pm 151$ & $589 \pm 347$ & 1.56 & {$[35]$} \\
\hline Vecuronium-carbamazepine & & & & & \\
\hline Vecuronium & Adult & $266 \pm 21$ & $630 \pm 84$ & 2.37 & {$[33]$} \\
\hline & $4-22$ & $378 \pm 151$ & $808 \pm 563$ & 2.13 & {$[35]$} \\
\hline
\end{tabular}


Table 1 (continued)

\begin{tabular}{|c|c|c|c|c|c|}
\hline Drugs & Age, years & Observed alone & Observed interaction & Ratio $^{a}$ & References \\
\hline \multicolumn{6}{|c|}{ Mycophenolate mofetil-tacrolimus (IV) } \\
\hline \multirow[t]{3}{*}{ Mycophenolate mofetil } & $>12$ to 16 & NA & $880 \pm 360$ & NA & {$[36]$} \\
\hline & $<6$ & NA & $550 \pm 197$ & NA & {$[36]$} \\
\hline & $6-12$ & NA & $725 \pm 335$ & NA & {$[36]$} \\
\hline \multicolumn{6}{|c|}{ Mycophenolate mofetil-cyclosporine } \\
\hline \multirow[t]{2}{*}{ Mycophenolate mofetil } & Adult & NA & $181 \pm 60$ & NA & {$[37]$} \\
\hline & $5-16$ & NA & $121 \pm 36$ & NA & {$[37]$} \\
\hline \multicolumn{6}{|c|}{ Rifabutin-lopinavir/ritonavir } \\
\hline \multirow[t]{2}{*}{ Rifabutin } & Adult & NA & $726 \pm N A$ & NA & {$[38]$} \\
\hline & $0.8-1.75$ & NA & $109 \pm 9$ & NA & [39] \\
\hline \multicolumn{6}{|l|}{ Sirolimus-cyclosporine } \\
\hline \multirow[t]{3}{*}{ Sirolimus } & Adult & NA & $162 \pm 73$ & NA & {$[40]$} \\
\hline & $6-11$ & NA & $96 \pm 58$ & NA & [40] \\
\hline & $12-18$ & NA & $118 \pm 49$ & NA & [40] \\
\hline
\end{tabular}

$N A$ not available, $I V$ intravenous

${ }^{\mathrm{a}}$ Ratio $=$ with/without interaction

\section{Discussion}

Drug-drug interactions can be therapeutically beneficial or subtherapeutic, or can lead to toxicity. Therefore, DDI studies have become an integral part of modern-day drug development and drug therapy. DDI studies are rarely performed in children. Drug interaction studies are generally conducted in adults and it is then assumed that a similar observation will be noted across younger age groups. This may be true but the magnitude of interaction in terms of ratios of the area under the curve or clearance (with/without interaction) may differ from adults to children (Table 1). It is also possible that a DDI may not occur in adults or will be of very small magnitude, but in children the interaction may be of clinical significance (Table 1).

This study is an attempt to predict the clearance of drugs in children following DDI studies. The adult clearance values used in this study were obtained following DDI studies, and the approach is based on an ADE model proposed by Mahmood et al. [41-45]. The predictive performance of this method was previously validated in several studies by external data and was found to be reliable (prediction error $\leq 50 \%$ or $\leq 30 \%$ ) [41-45]. In a recent study [45], the ADE model was compared with a physiologically based pharmacokinetic (PBPK) model and it was found that the predictive performance of both the ADE and PBPK models was comparable. The ADE model can be used from preterm neonates to adolescents based on fixed but variable age-dependent exponents. A recent publication with extensive data [46] further supported the previous observations [41-45] that the prediction of drug clearance from PBPK and ADE models is comparable across age groups. Other investigators $[47,48]$ also found that the ADE model is comparable with the PBPK model.
It should be noted that the allometric exponents are datadependent and are not fixed in nature. Depending on the availability of the data, allometric exponents should be determined (if allometry is applicable to the data). For example, in interspecies scaling, three to four species are enough to determine the exponents of the allometry. There are however situations where allometric exponents cannot be determined because only one species is available. When only one species is available, there is no choice but to use theoretical fixed exponents. The theoretical exponents generally used are 0.75 for clearance and 1.0 for volume of distribution.

The concept of variable but fixed allometric exponents across the age groups is an integral part of the ADE model. For example, when one is extrapolating clearance from adults to preterm neonates, there are no data to determine the allometric exponent for a given age group; hence, a fixed exponent is used in the ADE model. This method has been well-tested and the results are satisfactory [41-45] and comparable with other methods [42, 44-48].

It is a well-known fact that the clearance of a good majority of drugs across the age groups (neonates to adults) can be described allometrically (since the body weight range is wide) and the exponents of allometry will depend on the weight range and clearance values. In most cases, a single allometric exponent cannot describe clearance versus weight data across the entire age groups (preterm neonates to adults). Under such circumstances, two to three allometric exponents may be needed to accurately describe clearance versus weight data across age groups [42, 49-51].

The exponents of the ADE model are based on the observations of many authors of past publications [52-55], as well as body weight-dependent exponent (BDE) models [49-51]. The ADE model is simple compared with other 
Table 2 Predicted and observed clearance $(\mathrm{mL} / \mathrm{min})$ following drug-drug interactions in children

\begin{tabular}{|c|c|c|c|c|}
\hline Age (years) & Weight $(\mathrm{kg})$ & Observed CL & Predicted CL & Percentage error \\
\hline \multicolumn{5}{|c|}{ Theophylline-phenobarbital (effect on theophylline); adult $\mathrm{CL}=70 \pm 23 \mathrm{~mL} / \mathrm{min}$} \\
\hline Premature & $2.5(n=24)$ & $1.5 \pm 1.1$ & 1.3 & -14 \\
\hline $6-12$ & $32(n=7)$ & $53 \pm 23$ & 38 & -29 \\
\hline \multicolumn{5}{|c|}{ Zidovudine + dideoxyinosine (effect on zidovudine); adult $\mathrm{CL}=2505 \pm 575 \mathrm{~mL} / \mathrm{min}$} \\
\hline $3-14$ & $35(n=8)$ & $1260 \pm 515$ & 1489 & 18 \\
\hline \multicolumn{5}{|c|}{ Dideoxyinosine + zidovudine (effect on dideoxyinosine); adult $\mathrm{CL}=2766 \pm 686 \mathrm{~mL} / \mathrm{min}$} \\
\hline $3-14$ & $35(n=8)$ & $2870 \pm 1855$ & 1645 & 43 \\
\hline \multicolumn{5}{|c|}{ Levetiracetam + inducers (carbamazepine, oxcarbazepine, phenobarbital, phenytoin) } \\
\hline \multicolumn{5}{|c|}{ Adult $\mathrm{CL}=107 \pm 49 \mathrm{~mL} / \mathrm{min}$ (effect on levetiracetam) } \\
\hline 9.3 & $30(n=24)$ & $100 \pm 34$ & 57 & -43 \\
\hline \multicolumn{5}{|c|}{ Topiramate-carbamazepine (effect on topiramate); adult $\mathrm{CL}=51 \pm 11 \mathrm{~mL} / \mathrm{min}$} \\
\hline$<10$ & $30(n=4)$ & $42 \pm 9$ & 27 & -36 \\
\hline \multicolumn{5}{|c|}{ Topiramate-phenobarbital (effect on topiramate); adult $\mathrm{CL}=42 \pm 11 \mathrm{~mL} / \mathrm{min}$} \\
\hline$<10$ & $30(n=7)$ & $46 \pm 19$ & 22 & -52 \\
\hline $0.9-1.84$ & $13(n=3)$ & $17 \pm 2$ & 8 & -54 \\
\hline $2-3.7$ & $16(n=7)$ & $18 \pm 5$ & 10 & -47 \\
\hline \multicolumn{5}{|c|}{ Lamotrigine + carbamazepine and phenytoin (effect on lamotrigine) } \\
\hline \multicolumn{5}{|c|}{ Adult $\mathrm{CL}$ of lamotrigine with carbamazepine $=70 \pm \mathrm{NA} \mathrm{mL} / \mathrm{min}$; with phenytoin $=118 \pm \mathrm{NA} \mathrm{mL} / \mathrm{min}$} \\
\hline$<6$ & $15(n=3)$ & $31 \pm 11$ & 22 & -29 \\
\hline $7-14$ & $37(n=4)$ & $80 \pm 27$ & 58 & -28 \\
\hline \multicolumn{5}{|c|}{ Lamotrigine + valproic acid (effect on lamotrigine); adult $\mathrm{CL}=22 \pm 7 \mathrm{~mL} / \mathrm{min}$} \\
\hline $0.8-2$ & $11(n=3)$ & $6.5 \pm 3.8$ & $3.4 \pm 1.0$ & -48 \\
\hline $6-14$ & $29(n=4)$ & $13 \pm 16$ & $11 \pm 2.8$ & -15 \\
\hline \multicolumn{5}{|c|}{ Digoxin-carvedilol (effect on digoxin); adult $\mathrm{CL}=201 \pm 34 \mathrm{~mL} / \mathrm{min}$} \\
\hline $0.08-7.7$ & $8(n=8)$ & $20 \pm 3$ & 23 & 15 \\
\hline \multicolumn{5}{|c|}{ Artemether-neviraprine (effect on artemether); adult $\mathrm{CL}=33,057 \pm \mathrm{NA} \mathrm{mL} / \mathrm{min}$} \\
\hline 8.3 years & $18(n=15)$ & $10,103 \pm N A$ & 14,502 & 44 \\
\hline \multicolumn{5}{|c|}{ Lumefantrine (effect on lumefantrine); adult $\mathrm{CL}=35 \pm \mathrm{NA} \mathrm{mL} / \mathrm{min}$} \\
\hline 7.1 & $18(n=15)$ & $9 \pm \mathrm{NA}$ & 15 & 67 \\
\hline \multicolumn{5}{|c|}{ Etoposide-cyclosporine (effect on etoposide); adult $\mathrm{CL}=25 \pm 14 \mathrm{~mL} / \mathrm{min}$} \\
\hline $4.4-9.1$ & $40(n=6)$ & $13 \pm 4$ & $16 \pm 5$ & 23 \\
\hline $12.1-17$ & $50(n=6)$ & $16 \pm 7$ & $19 \pm 7$ & 19 \\
\hline $0.83-3.5$ & $11(n=2)$ & 7.4 & 4.7 & 36 \\
\hline 14 & $55(n=3)$ & $20 \pm 6$ & 21 & 4 \\
\hline \multicolumn{5}{|c|}{ Cyclosporine-grapefruit (effect on cyclosporine); adult $\mathrm{CL}=985 \pm 378 \mathrm{~mL} / \mathrm{min}$} \\
\hline $7-17$ & $44(n=6)$ & $1227 \pm 120$ & 695 & -43 \\
\hline \multicolumn{5}{|c|}{ Vecuronium-phenytoin (effect on vecuronium); adult $\mathrm{CL}=561 \pm \mathrm{NA} \mathrm{mL} / \mathrm{min}$} \\
\hline $5-17$ & $39(n=10)$ & $589 \pm 347$ & 362 & -39 \\
\hline \multicolumn{5}{|c|}{ Vecuronium-carbamazepine (effect on vecuronium); adult $\mathrm{CL}=630 \pm 84 \mathrm{~mL} / \mathrm{min}$} \\
\hline $4-22$ & $43(n=10)$ & $808 \pm 563$ & 437 & -46 \\
\hline \multicolumn{5}{|c|}{ Mycophenolate mofetil-tacrolimus (IV) [effect on mycophenolate] } \\
\hline \multicolumn{5}{|c|}{ From a clearance value of $880 \pm 360 \mathrm{~mL} / \mathrm{min}$ from adolescents $>12$ to 16 years of age (weight $=60 \mathrm{~kg}$ ) } \\
\hline$<6$ & $20(n=9)$ & $550 \pm 197$ & 386 & -30 \\
\hline $6-12$ & $30(n=5)$ & $725 \pm 335$ & 523 & -28 \\
\hline \multicolumn{5}{|c|}{ Mycophenolate mofetil-cyclosporine (effect on mycophenolate); adult CL $=181 \pm 60 \mathrm{~mL} / \mathrm{min}$} \\
\hline $5-16$ & $50(n=0)$ & $121 \pm 36$ & 141 & 16 \\
\hline Rifabutin-lol & rifabutin); ad & $726 \pm \mathrm{NA} \mathrm{mL} / 1$ & & \\
\hline $0.83-1.75$ & $9(n=3)$ & $109 \pm 9$ & 93 & -15 \\
\hline $2.42-3.42$ & $12(n=3)$ & $188 \pm 87$ & 138 & -27 \\
\hline Sirolimus-cy & imus); adult $\mathrm{C}$ & $\pm 73 \mathrm{~mL} / \mathrm{min}$ & & \\
\hline $6-11$ & $27(n=8)$ & $96 \pm 58$ & 79 & -18 \\
\hline $12-18$ & $52(n=14)$ & $118 \pm 49$ & 130 & 10 \\
\hline
\end{tabular}

Adult body weight normalized to $70 \mathrm{~kg}$. If the body weights of children were not provided in the article, then the weights were estimated from the body weight chart of the Centers for Disease Control and Prevention $(\mathrm{CDC})$ and from the literature

$C L$ clearance, $N A$ not available, $I V$ intravenous 
models (statistical empirical models as well as PBPK empirical models) and can be used in pediatric drug development to select first-in-children dose [41-45].

The metabolic enzymes and renal elimination mechanisms are quite immature during the early days of life. Therefore, the rate and extent of drug metabolism and elimination of drugs are different in children (particularly in neonates and infants) than adults. Similarly, the magnitude of DDIs may be different in neonates and infants than children. For example, in adults, an interaction can lead to a substantial increase in the clearance of one or both drugs, but, due to immature metabolic enzymes, the clearance may be very different (marginal change or no change at all) in very young children, especially preterm and term neonates. Therefore, in neonates and infants, extrapolation of a PK parameter from adult data can lead to serious prediction errors. Due to the paucity of DDI data in neonates and infants, a comprehensive analysis could not be performed in this study.

\section{Conclusion}

This study indicates that it is possible to predict the clearance of drugs with reasonable accuracy in children following DDI studies using an ADE model; however, there are many physiological and physical factors that may be hurdles for the prediction of drug clearance in children following DDI studies, but a reasonably accurate estimate of clearance is possible in children across the age groups using the proposed ADE model. It should be noted that the proposed method is not in lieu of a clinical trial, rather the methods should be used for the selection of first-in-children dose before initiating a pediatric DDI clinical trial. The proposed method is simple, robust, and reliable and can replace other complex empirical models. In an era of 'fit for purpose', simple models, if providing similar results, should be preferred over complex models that require too many covariates or too many and needless physiological parameters.

Acknowledgements The views expressed in this article are those of the author and do not reflect the official policy of the FDA or any private enterprise. No official support or endorsement by the FDA or any private enterprise is intended or should be inferred.

\section{Compliance with Ethical Standards}

Conflict of interest Iftekhar Mahmood declares that he has no conflicts of interest.

Funding No funding from the US FDA or any private enterprise was used to conduct this study or prepare this manuscript.

Open Access This article is licensed under a Creative Commons Attribution-NonCommercial 4.0 International License, which permits any non-commercial use, sharing, adaptation, distribution and reproduction in any medium or format, as long as you give appropriate credit to the original author(s) and the source, provide a link to the Creative Commons licence, and indicate if changes were made. The images or other third party material in this article are included in the article's Creative Commons licence, unless indicated otherwise in a credit line to the material. If material is not included in the article's Creative Commons licence and your intended use is not permitted by statutory regulation or exceeds the permitted use, you will need to obtain permission directly from the copyright holder.To view a copy of this licence, visit http://creativecommons.org/licenses/by-nc/4.0/.

\section{References}

1. Gibaldi M. Biopharmaceutics and clinical pharmacokinetics. Philadelphia: Lea and Febiger; 1984. p. 257-85.

2. US FDA. Guidance for industry: general clinical pharmacology considerations for pediatric studies for drugs and biological products. US FDA; 2014.

3. Salerno SN, Burckart GJ, Huang SM, Gonzalez D. Pediatric drug-drug interaction studies: barriers and opportunities. Clin Pharmacol Ther. 2019;105:1067-70.

4. Kearns GL, Abdel-Rahman SM, Alander SW, Blowey DL, Leeder JS, et al. Developmental pharmacology: drug disposition, action, and therapy in infants and children. N Engl J Med. 2003;349:1157-67.

5. Alcorn J, McNamara PJ. Ontogeny of hepatic and renal systemic clearance pathways in infants: part I. Clin Pharmacokinet. 2002;41:959-98.

6. Alcorn J, McNamara PJ. Ontogeny of hepatic and renal systemic clearance pathways in infants: part II. Clin Pharmacokinet. 2002;41:1077-94.

7. Benedetti MS, Baltes EL. Drug metabolism and disposition in children. Fund Clin Pharmacol. 2003;17:281-99.

8. Niederhauser VP. Prescribing for children: issues in pediatric pharmacology. Nurse Pract. 1997;22:16-8.

9. Blanco JG, Harrison PL, Evans WE, et al. Human cytochrome P450 maximal activities in pediatric versus adult liver. Drug Metab Dispos. 2000;28:379-82.

10. Arant BS Jr. Developmental patterns of renal functional maturation compared in the human neonate. J Pediatr. 1978;92:705-12.

11. Landay RA, Gonzalez MA, Taylor JC. Effect of phenobarbital on theophylline disposition. J Allergy Clin Immunol. 1978;62:27-9.

12. Kandrotas RJ, Cranfield TL, Gal P, Ransom JL, Weaver RL. Effect of phenobarbital administration on theophylline clearance in premature neonates. Ther Drug Monit. 1990;12:139-43.

13. Saccar CL, Danish M, Ragni MC, Rocci ML Jr, Greene J, Yaffe SJ, et al. The effect of phenobarbital on theophylline disposition in children with asthma. J Allergy Clin Immunol. 1985;75(6):716-9.

14. Barry M, Howe JL, Ormesher S, Back DJ, Breckenridge AM, Bergin $\mathrm{C}$, et al. Pharmacokinetics of zidovudine and dideoxyinosine alone and in combination in patients with the acquired immunodeficiency syndrome. Br J Clin Pharmacol. 1994;37:421-6.

15. Gibb D, Barry M, Ormesher S, Nokes L, Seefried M, Giaquinto $\mathrm{C}$, et al. Pharmacokinetics of zidovudine and dideoxyinosine alone and in combination in children with HIV infection. Br J Clin Pharmacol. 1995;39:527-30.

16. Hirsch LJ, Arif H, Buchsbaum R, Weintraub D, Lee J, Chang JT, et al. Effect of age and comedication on levetiracetam pharmacokinetics and tolerability. Epilepsia. 2007;48:1351-9.

17. Dahlin MG, Wide K, Ohman I. Age and comedications influence levetiracetam pharmacokinetics in children. Pediatr Neurol. 2010;43:231-5.

18. Battino D, Croci D, Rossini A, Messina S, Mamoli D, Perucca E. Topiramate pharmacokinetics in children and adults with epilepsy: 
a case-matched comparison based on therapeutic drug monitoring data. Clin Pharmacokinet. 2005;44:407-16.

19. Mikaeloff Y, Rey E, Soufflet C, d'Athis P, Echenne B, Vallée L, et al. Topiramate pharmacokinetics in children with epilepsy aged from 6 months to 4 years. Epilepsia. 2004;45:1448-52.

20. Glauser TA, Miles MV, Tang P, Clark P, McGee K, Doose DR. Topiramate pharmacokinetics in infants. Epilepsia. 1999;40:788-91.

21. Weintraub D, Buchsbaum R, Resor SR Jr, Hirsch LJ. Effect of antiepileptic drug comedication on lamotrigine clearance. Arch Neurol. 2005;62:1432-6.

22. Battino D, Croci D, Granata T, Mamoli D, Messina S, Perucca E. Single-dose pharmacokinetics of lamotrigine in children: influence of age and antiepileptic comedication. Ther Drug Monit. 2001;23:217-22.

23. Chen C, Casale EJ, Duncan B, Culverhouse EH, Gilman J. Pharmacokinetics of lamotrigine in children in the absence of other antiepileptic drugs. Pharmacotherapy. 1999;19:437-41.

24. Wermeling DP, Field CJ, Smith DA, Chandler MH, Clifton GD, Boyle DA. Effects of long-term oral carvedilol on the steady-state pharmacokinetics of oral digoxin in patients with mild to moderate hypertension. Pharmacotherapy. 1994;14:600-6.

25. Ratnapalan S, Griffiths K, Costei AM, Benson L, Koren G. Digoxin-carvedilol interactions in children. J Pediatr. 2003;142:572-4.

26. Byakika-Kibwika P, Lamorde M, Mayito J, Nabukeera L, Namakula R, Mayanja-Kizza H, et al. Significant pharmacokinetic interactions between artemether/lumefantrine and efavirenz or nevirapine in HIV-infected Ugandan adults. J Antimicrob Chemother. 2012;67:2213-21.

27. Huang L, Carey V, Lindsey JC, Marzan F, Gingrich D, Graham B, IMPAACT P1079 protocol team, et al. Concomitant nevirapine impacts pharmacokinetic exposure to the antimalarial artemetherlumefantrine in African children. PLoS One. 2017;12:e0186589.

28. Lum BL, Kaubisch S, Yahanda AM, Adler KM, Jew L, Ehsan MN, et al. Alteration of etoposide pharmacokinetics and pharmacodynamics by cyclosporine in a phase I trial to modulate multidrug resistance. J Clin Oncol. 1992;10:1635-42.

29. Bisogno G, Cowie F, Boddy A, Thomas HD, Dick G, Pinkerton CR. High-dose cyclosporin with etoposide-toxicity and pharmacokinetic interaction in children with solid tumours. Br J Cancer. 1998;77:2304-9.

30. Kersting G, Willmann S, Würthwein G, Lippert J, Boos J, Hempel G. Physiologically based pharmacokinetic modelling of high- and low-dose etoposide: from adults to children. Cancer Chemother Pharmacol. 2012;69:397-405.

31. Hermann M, Asberg A, Reubsaet JL, Sather S, Berg KJ, Christensen $\mathrm{H}$. Intake of grapefruit juice alters the metabolic pattern of cyclosporin A in renal transplant recipients. Int J Clin Pharmacol Ther. 2002;40:451-6.

32. Brunner LJ, Pai KS, Munar MY, Lande MB, Olyaei AJ, Mowry JA. Effect of grapefruit juice on cyclosporin A pharmacokinetics in pediatric renal transplant patients. Pediatr Transpl. 2000;4:313-21.

33. Wright PM, McCarthy G, Szenohradszky J, Sharma ML, Caldwell JE. Influence of chronic phenytoin administration on the pharmacokinetics and pharmacodynamics of vecuronium. Anesthesiology. 2004;100:626-33.

34. Alloul K, Whalley DG, Shutway F, Ebrahim Z, Varin F. Pharmacokinetic origin of carbamazepine-induced resistance to vecuronium neuromuscular blockade in anesthetized patients. Anesthesiology. 1996;84:330-9.

35. Soriano SG, Sullivan LJ, Venkatakrishnan K, Greenblatt DJ, Martyn JA. Pharmacokinetics and pharmacodynamics of vecuronium in children receiving phenytoin or carbamazepine for chronic anticonvulsant therapy. Br J Anaesth. 2001;86:223-9.
36. Bhatia M, Militano O, Jin Z, Figurski M, Shaw L, Moore V, et al. An age-dependent pharmacokinetic study of intravenous and oral mycophenolate mofetil in combination with tacrolimus for GVHD prophylaxis in pediatric allogeneic stem cell transplantation recipients. Biol Blood Marrow Transpl. 2010;16:333-43.

37. US FDA. Package insert. MYFORTIC ${ }^{\circledR}$ (mycophenolic acid) delayed-release tablets, for oral use. Initial U.S. Approval. US FDA; 2004.

38. Boulanger C, Hollender E, Farrell K, Stambaugh JJ, Maasen D, Ashkin D, et al. Pharmacokinetic evaluation of rifabutin in combination with lopinavir-ritonavir in patients with HIV infection and active tuberculosis. Clin Infect Dis. 2009;49:1305-11.

39. Moultrie H, McIlleron H, Sawry S, Kellermann T, Wiesner L, Kindra G, et al. Pharmacokinetics and safety of rifabutin in young $\mathrm{HIV}$-infected children receiving rifabutin and lopinavir/ritonavir. J Antimicrob Chemother. 2015;70:543-9.

40. US FDA. Package insert. RAPAMUNE (sirolimus) oral solution and RAPAMUNE (sirolimus) tablets, for oral use. Initial U.S. Approval. US FDA; 1999.

41. Mahmood I. Prediction of drug clearance in premature and mature neonates, infants, and children $\leq 2$ years of age: a comparison of the predictive performance of 4 allometric models. J Clin Pharmacol. 2016;56:733-9.

42. Mahmood I, Staschen CM, Goteti K. Prediction of drug clearance in children: an evaluation of the predictive performance of several models. AAPS J. 2014;16:1334-43.

43. Mahmood I. Mechanistic versus allometric models for the prediction of drug clearance in neonates $(<3$ months of age). J Clin Pharmacol. 2015;55:718-20.

44. Mahmood I, Ahmad T, Mansoor N, Sharib SM. Prediction of clearance in neonates and infants ( $\leq 3$ months of age) for drugs that are glucuronidated: a comparative study between allometric scaling and physiologically based pharmacokinetic modeling. J Clin Pharmacol. 2017;57(4):476-83.

45. Mahmood I, Tegenge MA. a comparative study between allometric scaling and physiologically based pharmacokinetic modeling for the prediction of drug clearance from neonates to adolescents. J Clin Pharmacol. 2019;59:189-97.

46. Wu Q, Peters SA. A retrospective evaluation of allometry, population PK and PBPK for pediatric dosing using clearance as a surrogate. CPT Pharmacomet Syst Pharmacol. 2019;8:220-9.

47. Malik PRV, Edginton AN. Physiologically-based pharmacokinetic modeling vs. allometric scaling for the prediction of infliximab pharmacokinetics in pediatric patients. CPT Pharmacomet Syst Pharmacol. 2019;8:835-44.

48. Huisinga W, Solms A, Fronton L, Pilari S. Modeling interindividual variability in physiologically based pharmacokinetics and its link to mechanistic covariate modeling. CPT Pharmacomet Syst Pharmacol. 2012;1:e4.

49. Wang C, Allegaert K, Peeters MY, Tibboel D, Danhof M, Knibbe $\mathrm{CA}$. The allometric exponent for scaling clearance varies with age: a study on seven propofol datasets ranging from preterm neonates to adults. Br J Clin Pharmacol. 2014;77:149-59.

50. Bartelink IH, Boelens JJ, Bredius RG, Egberts AC, Wang C, et al. Body weight-dependent pharmacokinetics of busulfan in paediatric haematopoietic stem cell transplantation patients: towards individualized dosing. Clin Pharmacokinet. 2012;51:331-45.

51. Wang C, Sadhavisvam S, Krekels EH, Dahan A, Tibboel D, Danhof $\mathrm{M}$, et al. Developmental changes in morphine clearance across the entire paediatric age range are best described by a bodyweightdependent exponent model. Clin Drug Investig. 2013;33:523-34.

52. Brody S. Bioenergetics and growth, with special reference to the efficiency complex in domestic animals. New York/London: Hafner Press/MacMillan Publishers; 1945.

53. Chappell WR, Mordenti J. The use of interspecies scaling in toxicokinetics. In: Yacobi A, Skelly JP, Batra VK, editors. 
Toxicokinetics and new drug development. New York: Pergamon Press; 1989.

54. Wieser W. A distinction must be made between the ontogeny and the phylogeny of metabolism in order to understand the mass exponent of energy metabolism. Respir Physiol. 1984;55:1-9.
55. McMahon TA, Bonner JT. Proportions and size. In: McMahon T, Bonner JT, editors. On size and life. New York: Scientific American Library; 1983. p. 25-67. 